\title{
Efficacy and Tolerability of Paliperidone Extended-release in the Treatment of First-episode Psychosis: An Eight-week, Open-label, Multicenter Trial
}

\author{
Nam-In Kang ${ }^{1}$, Bon-Hoon Koo ${ }^{2}$, Sung-Wan Kim ${ }^{3}$, Jong-Hoon Kim ${ }^{4}$, Beomwoo Nam ${ }^{5}$, Bong-Ju Lee ${ }^{6}$, \\ Sang-Hyuk Lee ${ }^{7}$, Seung Jae Lee ${ }^{8}$, Seung-Hwan Lee ${ }^{9}$, Myung Hun Jung ${ }^{10}$, Sang Woo Hahn ${ }^{11}$, \\ Young-Chul Chung ${ }^{12,13}$ \\ 'Department of Psychiatry, Maeumsarang Hospital, Wanju, ${ }^{2}$ Department of Psychiatry, Yeungnam University, Gyeongsan, ${ }^{3}$ Department of \\ Psychiatry, Chonnam National University Medical School, Gwangju, ${ }^{4}$ Department of Psychiatry, Gachon University Gil Medical Center, \\ Gachon University School of Medicine, Incheon, ${ }^{5}$ Department of Psychiatry, Konkuk University School of Medicine, Cheongju, ${ }^{6}$ Department \\ of Psychiatry, Inje University Haeundae Paik Hospital, Inje University College of Medicine, Busan, ${ }^{7}$ Department of Psychiatry, CHA Bundang \\ Medical Center, CHA University, Seongnam, ${ }^{8}$ Department of Psychiatry, Kyoungpook National University School of Medicine, Daegu, \\ ${ }^{9}$ Department of Psychiatry, Inje University Ilsan Paik Hospital, Goyang, ${ }^{10}$ Department of Psychiatry, Hallym University Sacred Heart Hospital, \\ Anyang, "Department of Psychiatry, Soonchunhyang University Seoul Hospital, Soonchunhyang University College of Medicine, Seoul, \\ ${ }^{12}$ Department of Psychiatry, Chonbuk National University Hospital, Jeonju, ${ }^{13}$ Research Institute of Clinical Medicine of Chonbuk National \\ University-Biomedical Research Institute of Chonbuk National University Hospital, Jeonju, Korea
}

\begin{abstract}
Objective: We investigated the efficacy and tolerability of paliperidone extended-release (ER) tablets in patients with first-episode psychosis ( $n=75$ ).

Methods: This was an 8-week, open-label, multicenter trial. The primary outcome variable was scores on the Positive and Negative Syndrome Scale (PANSS); secondary measures included the Scale for the Assessment of Negative Symptoms (SANS), the Cognitive Assessment Interview (CAl), and the Global Assessment of Functioning (GAF). To assess safety, we measured drug-related adverse events, weight, lipid-related variables, and prolactin and administered the Simpson-Angus Rating Scale (SARS), the Abnormal Involuntary Movement Scale (AIMS), the Barnes Akathisia Scale (BAS), the Arizona Sexual Experiences Scale (ASEX), and the Udvalg for Kliniske Undersogelser side effect rating scale (UKU).

Results: The administration of paliperidone ER resulted in significant improvement in the PANSS, SANS, CAI, and GAF scores $(p<0.001)$ over time. This improvement was evident as early as 1 week. The most frequent adverse events were akathisia, somnolence, anxiety, and sedation, which were well tolerated. Modest increases in weight and lipid profiles were also noted. Prolactin levels were substantially increased at the endpoint in both male and female patients.

Conclusion: These results indicate that paliperidone ER is effective and is characterized by good tolerability in the treatment of positive and negative symptoms and cognitive functioning in first-episode psychosis.
\end{abstract}

KEY WORDS: Paliperidone extended-release; First-episode psychosis; Efficacy; Tolerability.

\section{INTRODUCTION}

Successful pharmacological treatment of patients with first-episode psychosis is very important because rapid drug response with good safety can affect drug compliance and maintenance treatment. Generally, first-episode psychosis patients have better therapeutic responses to antipsychotics than chronic, multi-episode patients. ${ }^{1,2}$

\footnotetext{
Received: November 26, 2015 / Revised: January 3, 2016

Accepted: January 4, 2016

Address for correspondence: Young-Chul Chung, MD, PhD Department of Psychiatry, Chonbuk National University Medical School, 20 Geonji-ro, Deokjin-gu, Jeonju 54907, Korea Tel: +82-63-250-2185, Fax: +82-63-275-3157 E-mail: chungyc@jbnu.ac.kr
}

Nevertheless, numerous patients with early psychosis or first-episode schizophrenia discontinue their initial medication due to lack of efficacy ${ }^{3)}$ or drug side effects. ${ }^{4,5)}$ The discontinuation rates due to lack of efficacy range from $9 \%$ to $48 \%{ }^{6}{ }^{6}$ First-episode patients are more sensitive to drug side effects and have higher rates of symptoms such as extrapyramidal signs (EPSs) ${ }^{7}$ and antipsychotic-induced weight gain. ${ }^{8,9)}$ Consequently, experiencing drug side effects during the initial phase of treatment negatively affects future drug compliance. ${ }^{10,11)}$ Thus, choosing a first-line antipsychotic drug with superior efficacy and good safety for the patients with first-episode psychosis should be the highest priority for clinicians.

Paliperidone is the major active metabolite of risper-

(c) This is an Open-Access article distributed under the terms of the Creative Commons Attribution Non-Commercial License (http://creativecommons.org/licenses/by-nc/4.0) which permits unrestricted non-commercial use, distribution, and reproduction in any medium, provided the original work is properly cited. 
idone, a second-generation antipsychotic drug with potent antagonistic properties at serotonin 5- $\mathrm{HT}_{2 \mathrm{~A}}$ and dopamine D2 receptors, some affinity towards H1-receptors, $\alpha 1$ and $\alpha 2$-adrenergic receptors, and no effective affinity towards muscarinic receptors or $\beta 1$ - and $\beta 2$-adrenergic receptors. ${ }^{12)}$ Paliperidone extended-release (ER) is an atypical antipsychotic with an innovative ER delivery system, Osmotic-Controlled Release Oral Delivery System (OROS) technology. The drug minimizes peak-trough fluctuations and, by obviating dose titration, allows once-daily dosing with a therapeutically active dose from the first day. ${ }^{13)}$ The low peak-trough fluctuations are reported to be associated with better tolerability such as reduced rates of extrapyramidal symptoms and somnolence. ${ }^{14)}$ Several randomized, double-blind, placebo-controlled trials have shown that paliperidone ER is an effective, safe, and well-tolerated treatment for schizophrenia $^{15)}$ and schizoaffective disorders. ${ }^{16)}$ The pooled data analysis of three 6-week, placebo-controlled studies showed that treatment with paliperidone ER produced a clinical response of at least a $30 \%$ improvement in the Positive and Negative Syndrome Scale (PANSS) total score of approximately $50 \%$ of patients with acute schizophrenia. ${ }^{17)}$ However, to the best of our knowledge, there is only one open-label report of the clinical trial with paliperidone ER in patients with first-episode schizophrenia. ${ }^{18)}$ Considering its unique pharmacokinetic characteristics, we hypothesized that a treatment response would appear earlier and its effects on prolactin levels would be lesser than risperidone. In the present study, we conducted an 8-week, open-label, prospective trial to investigate the efficacy and tolerability of paliperidone ER in acutely ill first-episode inpatients with a primary psychiatric diagnosis of schizophrenia, schizophreniform disorder, schizoaffective disorder, or psychotic disorder, not otherwise specified.

\section{METHODS}

\section{Participants}

Patients 18-59 years of age who met the Diagnostic and Statistical Manual of Mental Disorders, fourth edition (DSM-IV) criteria for first-episode schizophrenia, schizophreniform disorder, schizoaffective disorder, or psychotic disorder not otherwise specified (NOS), as assessed using the Structured Clinical Interview for DSM-IV Axis I disorders ${ }^{19)}$ (SCID-I), were eligible to participate in the study. Patients were included if they had symptoms requiring antipsychotic treatment (a score of $\geq 4$ [moderate] on at least one of the following: the PANSS ${ }^{20)}$ positive items: PI, P2, P3, P5, and P6 or Clinical Global Impression [CGI] score 24 ) with illness duration of more than 1 month and less than 60 months, ${ }^{21)}$ and no lifetime history of previous antipsychotic exposure lasting for 2 or more consecutive weeks. ${ }^{6}$ Patients were excluded from the trial for any of the following reasons: (i) meeting DSM-IV criteria for another axis I diagnosis, including substance abuse or dependence and mental retardation (IQ $\leq 70$ ); (ii) need for treatment with antidepressants, mood stabilizers, benzodiazepines (except as prescribed for agitation and control of EPSs), anticonvulsants; or (iii) a serious or unstable medical illness. Pregnant or lactating women and women without adequate contraception were also excluded. All enrolled patients provided written informed consent. The trial was approved by the local institutional review boards (approval No., CUH2009-12-141) and registered in ClinicalTrials.gov Protocol Registration and Results System (NCT01157585).

\section{Study Design}

An 8-week, open-label, single-arm clinical trial was conducted in 14 university hospitals in Korea between December 2009 and March 2013. The study consisted of screening, baseline, and assessments at 1, 2, 3, 4 and 8 weeks. To achieve reliable assessments of the major rating scales among the centers, approved raters were trained twice at the pre-investigation meetings. Patients concurrently receiving antipsychotics underwent a washout period of at least 3 days. Paliperidone ER was administered once daily in the morning, but it was allowed in the evening in the case of excessive sedation. The initial recommended dose was 3-6 mg/day. Within 2 weeks, the dose could be increased to a maximum of $12 \mathrm{mg} /$ day, depending on the patient's condition. Patients in whom the treatment was considered ineffective were excluded from the study after 3 weeks. Insufficient efficacy was determined based on CGI-Improvement (CGI-I) scores of 3 or more (minimally improved) after at least 1 week of administration of paliperidone ER at a dose of $12 \mathrm{mg}$ /day and after at least a 3-week trial. Patients who were intolerant of the medication's adverse effects at any time were excluded from the study. To control aggressive and threatening behavior during admission, injection of haloperidol plus lorazepam was allowed once only. During the remainder of the study, injection of lorazepam or seclusion was used for behavior control. Concomitant lorazepam (for insomnia or agitation), benztropine (EPS), and $\beta$ adrenoceptor antagonists (for akathisia) were allowed if 
necessary during the study, but they were not administered prophylactically. Use of antidepressants and mood stabilizers were allowed in patients with schizoaffective disorder or other disorders with significant depression. Adding other antipsychotics was strictly prohibited. Poor drug compliance was defined as not taking more than $1 / 3$ of the medication in a given period between evaluation time points. Patients showing poor compliance over two consecutive periods were excluded from the study.

\section{Efficacy Assessments}

The PANSS ${ }^{20)}$ was used to determine the effect of paliperidone ER on overall psychopathology. Primary efficacy was rated as changes in the PANSS total score between baseline and 1, 2, 3, 4, and 8 weeks. The secondary efficacy variables were the total score (the sum of all 24 items) on the Scale for the Assessment of Negative Symptoms (SANS), ${ }^{22)}$ Cognitive Assessment Interview $(\mathrm{CAI}){ }^{23)}$ and the Global Assessment of Functioning (GAF). ${ }^{24)}$ Discontinuation due to insufficient clinical responses and/or adverse events was recorded. Efficacy variables, with the exception of CAI and GAF, were measured at baseline (day 0) and 1, 2, 3, 4, and 8 weeks. The $\mathrm{CAI}$ and GAF were assessed at baseline and 8 weeks.

\section{Safety and Tolerability Assessments}

All adverse events reported and observed during the study or within 6 days from the last day of treatment were recorded. The severity, duration, and possible relationship of all adverse events to the study drugs were recorded. The occurrence of parkinsonism, akathisia, and dyskinesia was evaluated at baseline and at every visit or upon early termination using standardized EPS rating scales: Simpson-Angus Rating Scale (SARS), ${ }^{25)}$ Barnes Akathisia Scale (BAS), ${ }^{26)}$ and Abnormal Involuntary Movement Scale (AIMS). ${ }^{27)}$ Arizona Sexual Experiences Scale $(\mathrm{ASEX})^{28)}$ and sexual side effect items of the Udvalg for Kliniske Undersogelser side-effect rating scale (UKU) ${ }^{29)}$ were also administered at baseline and at 4 and 8 weeks for the evaluation of sexual adverse events. Weight, body mass index (BMI), and prolactin levels were measured at baseline and at 8 weeks. Electrocardiography and laboratory studies (complete blood cell count, electrolytes, kidney and liver function tests, and fasting lipids, including triglycerides [TG], total cholesterol, high-density lipoprotein [HDL], and low-density lipoprotein [LDL] levels) were conducted at baseline and endpoint (8 weeks).

\section{Statistical Analyses}

All efficacy and safety variables were evaluated using an intent-to-treat analysis with the last observation carried forward. Patients were included in the efficacy and tolerability analyses only if baseline measurements and at least one post-baseline measurement or observation after medication were performed. To evaluate changes in symptom scores between different assessment time points, repeatedmeasures analysis of variance (ANOVA) was used, with the Bonferroni post hoc test for multiple comparisons. Effect size was calculated using the following formula: after mean-baseline mean/baseline standard deviation (SD). Analyses of weight and laboratory measures from baseline to endpoint were performed using paired $t$-tests or Wilcoxon's signed-rank tests. In all analyses, a $p$ value $<0.05$ was considered to indicate statistical significance.

\section{RESULTS}

\section{Demographic and Clinical Characteristics of Patients}

Of the 82 eligible patients, 75 (41 males and 34 females) consented to participate in the study. The mean age, educational level, and duration of untreated psychosis (DUP) were $30.8 \pm 11.0$ years, $12.7 \pm 3.0$ years, and $15.5 \pm 19.5$ months, respectively. The diagnoses of participants were as follows: schizophrenia ( $\mathrm{n}=49)$, schizophreniform disorder $(n=16)$, schizoaffective disorder $(n=2)$, and psychotic disorder NOS $(n=8)$ (Table 1$)$. At the time of enrollment, the numbers of antipsychotic-naïve, -free, and -treated patients were 55,16 , and 4 , respectively. Of these 75,51 patients $(68.0 \%)$ were able to complete the 8 -week trial (Fig. 1). The reasons for exclusion were loss of follow up (9), withdrawal of consent (5), lack of efficacy (5), intolerable side effects (2), use of prohibited medications

Table 1. Demographic and clinical characteristics of enrolled patients $(n=75)$

\begin{tabular}{lc}
\hline \multicolumn{1}{c}{ Characteristic } & Data \\
\hline Sex & $41(54.7)$ \\
Male & $34(45.3)$ \\
Female & $30.8 \pm 11.0$ \\
Age (yr) & $12.7 \pm 3.0$ \\
Education (yr) & $15.5 \pm 19.5$ \\
DuP (mo) & \\
Diagnosis & $49(65.3)$ \\
Schizophrenia & $16(21.3)$ \\
Schizophreniform disorder & $2(2.7)$ \\
Schizoaffective disorder & $8(10.7)$ \\
Psychotic disorder Nos &
\end{tabular}

Values are presented as number (\%) or mean \pm standard deviation. DUP, duration of untreated psychosis; NOS, not otherwise specified. 


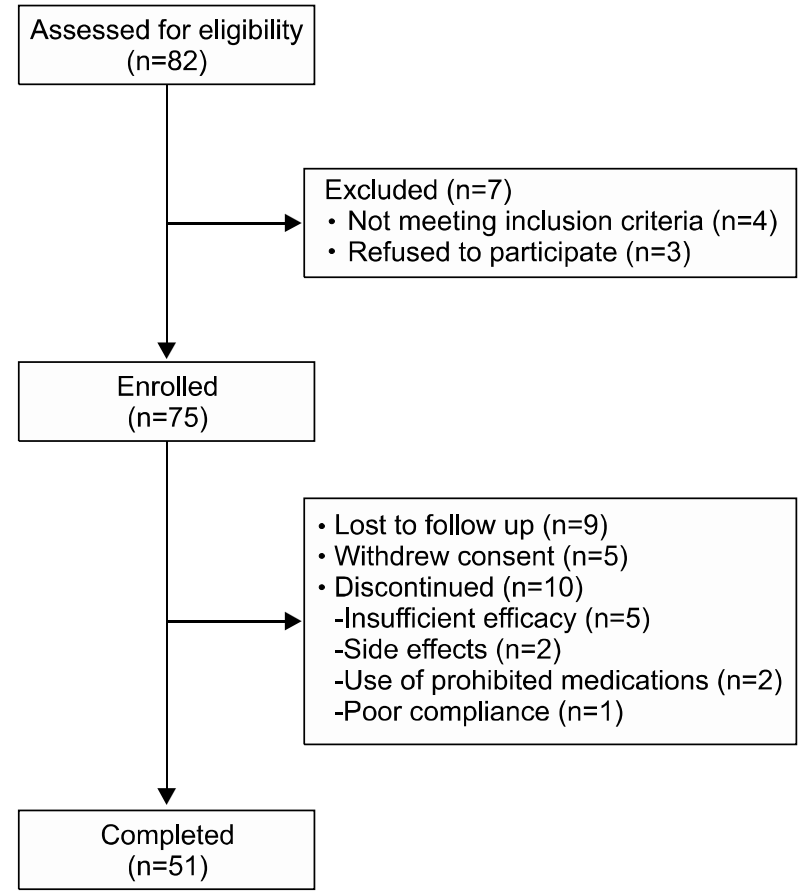

Fig. 1. CONSORT flow of participants through the trial.
(2), and poor drug compliance (1). No differences in demographic or baseline clinical characteristics were found between the patients who completed the study and those who did not (data not shown).

\section{Dosage and Concomitant Medications}

The mean total daily doses of paliperidone ER at baseline and endpoint were $4.63 \pm 1.67$ and $8.74 \pm 2.78 \mathrm{mg} /$ day, respectively. There were no significant differences in dosage between males and females across all time points. The percentages of patients who required benztropine, a $\beta$-adrenoceptor antagonist, and bgenzodiazepine at any time during the study were $62.7 \%, 35.3 \%$, and $64.7 \%$, respectively.

\section{Efficacy}

Table 2 shows significant reductions in the psychopathology scores (PANSS and SANS) over time, whereas significant increases were observed in the CAI and GAF scores between baseline and endpoint. Significant reductions in the total and subscale scores of the PANSS and SANS were observed as early as 1 week. The largest effect size was observed in the positive PANSS subscale score.

Table 2. Results on primary and secondary outcome measures over time (LOCF) ( $n=75)$

\begin{tabular}{|c|c|c|c|c|c|c|c|c|}
\hline & Baseline & 1-Week & 2-Week & 3-Week & 4-Week & 8-Week & $p$ value & $\begin{array}{c}\text { Effect } \\
\text { size }\end{array}$ \\
\hline \multicolumn{9}{|l|}{ PANSS } \\
\hline Positive total & $26.40 \pm 5.97$ & $21.57 \pm 6.14^{*}$ & $18.89 \pm 5.53^{*}+$ & $17.35 \pm 4.86^{*} \cdot+. \neq$ & $15.91 \pm 5.00^{*}+\uparrow . \S$ & $15.09 \pm 5.14^{*, \dagger, キ, \S . ? ~}$ & $<0.001$ & 1.894 \\
\hline Negative total & $22.27 \pm 6.15$ & $19.91 \pm 5.25^{\star}$ & $18.57 \pm 5.18^{* \dagger}$ & $17.84 \pm 5.26^{*, \dagger}$ & $16.85 \pm 4.82^{*, \dagger . キ . \S}$ & $16.00 \pm 4.97^{*, \dagger . キ . \S}$ & $<0.001$ & 1.020 \\
\hline General total & $50.88 \pm 11.78$ & $43.39 \pm 12.09^{*}$ & $40.11 \pm 11.54^{*}+$ & $38.49 \pm 11.26^{* \dagger}$ & $36.72 \pm 11.05^{*}$, , キ.§ & $34.79 \pm 10.59^{*,+, \neq . \S .9 ~}$ & $<0.001$ & 1.366 \\
\hline Composite total & $99.55 \pm 20.25$ & $84.87 \pm 21.27^{\star}$ & $77.57 \pm 20.16^{*}+$ & $73.68 \pm 19.69^{*}$. & $69.48 \pm 19.27^{*, \dagger . \neq . \S ~}$ & $65.88 \pm 19.23^{*, \dagger, キ . \S . 币 ~}$ & $<0.001$ & 1.663 \\
\hline \multicolumn{9}{|c|}{ 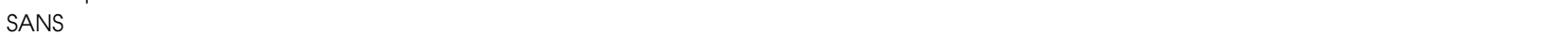 } \\
\hline Affective blunting & $10.52 \pm 5.12$ & $8.60 \pm 4.59^{*}$ & $7.56 \pm 4.55^{\star+}+$ & $7.28 \pm 4.78^{*+\dagger}$ & $6.87 \pm 4.51^{*, \dagger}$ & $6.28 \pm 4.38^{* . \dagger . キ . \S ~}$ & $<0.001$ & 0.829 \\
\hline Alogia & $7.61 \pm 4.38$ & $5.71 \pm 3.59^{*}$ & $4.77 \pm 3.23^{*}+$ & $4.67 \pm 3.33^{*}, \dagger$ & $4.49 \pm 3.21^{\star . \dagger}$ & $4.19 \pm 3.18^{* .}$ & $<0.001$ & 0.783 \\
\hline Avolition-apathy & $6.13 \pm 2.63$ & $4.84 \pm 2.43^{*}$ & $4.32 \pm 2.55^{\star, \dagger}$ & $4.04 \pm 2.56^{* . \dagger}$ & $3.79 \pm 2.61^{*, t, \neq}$ & $3.41 \pm 2.57^{*, \dagger, \neq . \S}$ & $<0.001$ & 1.035 \\
\hline Anhedonia-asociality & $9.12 \pm 3.85$ & $7.64 \pm 3.75^{\star}$ & $6.85 \pm 3.73^{*}+$ & $6.41 \pm 3.68^{*}+$ & $5.93 \pm 3.64^{*, \dagger, キ . \S ~}$ & $5.61 \pm 3.66^{*, \dagger . \neq . \S}$ & $<0.001$ & 0.911 \\
\hline Attention & $3.95 \pm 2.13$ & $3.19 \pm 1.78^{*}$ & $2.88 \pm 1.80^{\star}$ & $2.61 \pm 1.79^{*}+$ & $2.45 \pm 1.80^{*}+. \neq$ & $2.36 \pm 1.83^{*}+$ & $<0.001$ & 0.745 \\
\hline Total score $e^{\star *}$ & $48.09 \pm 18.98$ & $21.57 \pm 6.14^{*}$ & $18.89 \pm 5.53^{*}+$ & $17.35 \pm 4.86^{*}+$ & $15.91 \pm 5.00^{*}+$, & $15.09 \pm 5.14^{* . \dagger . キ . \S}$ & $<0.001$ & 1.739 \\
\hline \multicolumn{9}{|l|}{$\mathrm{CAl}(\mathrm{n}=51)$} \\
\hline Working memory & $2.39 \pm 1.25$ & NA & NA & NA & NA & $1.70 \pm 0.73$ & $<0.001$ & 0.552 \\
\hline Attention vigilance & $2.44 \pm 1.15$ & NA & NA & NA & NA & $1.76 \pm 0.66$ & $<0.001$ & 0.591 \\
\hline $\begin{array}{l}\text { Verbal learning } \\
\text { and memory }\end{array}$ & $2.57 \pm 1.33$ & NA & NA & NA & NA & $1.82 \pm 0.81$ & $<0.001$ & 0.564 \\
\hline $\begin{array}{l}\text { Reasoning and } \\
\text { problem solving }\end{array}$ & $2.23 \pm 1.16$ & NA & NA & NA & NA & $1.45 \pm 0.55$ & $<0.001$ & 0.672 \\
\hline Speed of processing & $2.80 \pm 1.43$ & NA & NA & NA & NA & $2.03 \pm 0.94$ & $<0.001$ & 0.538 \\
\hline Social cognition & $2.78 \pm 1.31$ & NA & NA & NA & NA & $1.86 \pm 0.86$ & $<0.001$ & 0.702 \\
\hline Global severity score & $2.66 \pm 1.14$ & NA & NA & NA & NA & $1.92 \pm 0.72$ & $<0.001$ & 0.649 \\
\hline GAF $(n=51)$ & $54.80 \pm 17.46$ & NA & NA & NA & NA & $66.35 \pm 9.16$ & $<0.001$ & 0.662 \\
\hline
\end{tabular}

Values are presented as mean \pm standard deviation.

$*,+, \neq, \$$, Statistically significant difference from the baseline, 1-week, 2-week, 3-week, and 4-week $(p<0.05)$ with Bonferroni correction; $p$, one-way repeated measures ANOVA; Effect size=(after mean-baseline mean)/ baseline standard deviation.

${ }^{*}$ Sum of the item $1-24$.

LOCF, last observation carried forward; PANSS, Positive and Negative Syndrome Scale; SANS, Scale for the Assessment of Negative Symptoms; CAl, Cognitive Assessment Interview; GAF, Global Assessment of Functioning; NA, not available. 


\section{Safety and Tolerability}

Overall, the most frequent adverse events were akathisia, somnolence, anxiety, and sedation (Table 3). Adverse events were observed primarily early during the course of treatment, at 1 or 2 weeks. The incidences of treatment-emergent adverse events (TEAE) over 8 weeks were as follows: akathisia (41.3\%), somnolence (24.0\%), EPS (22.7\%), and sedation (20.0\%). However, they were mostly mild and transient. The TEAE of moderate severity reported at two time points by the same patient were

Table 3. Incidence of adverse events observed in patients over the course of treatment

\begin{tabular}{|c|c|c|c|c|c|c|c|}
\hline Variable & $\begin{array}{l}\text { Baseline } \\
(n=75)\end{array}$ & $\begin{array}{l}\text { After } 1 \text {-week } \\
\quad(n=74)\end{array}$ & $\begin{array}{l}\text { After 2-week } \\
\qquad(n=74)\end{array}$ & $\begin{array}{l}\text { After 3-week } \\
\quad(n=67)\end{array}$ & $\begin{array}{c}\text { After } 4 \text {-week } \\
\quad(n=62)\end{array}$ & $\begin{array}{l}\text { After } 8 \text {-week } \\
\quad(n=51)\end{array}$ & $p$ value \\
\hline \multicolumn{8}{|l|}{ Check list } \\
\hline Headache & $10(13.3)$ & $8(10.8)$ & $3(4.1)$ & $5(7.5)$ & $6(9.7)$ & $4(7.8)$ & \\
\hline Akathisia & NA & $13(17.6)$ & $19(25.7)$ & $14(20.9)$ & $9(14.5)$ & $7(13.7)$ & \\
\hline Insomnia & $12(16.0)$ & $9(12.2)$ & $8(10.8)$ & $7(10.4)$ & $5(8.1)$ & $3(5.9)$ & \\
\hline Somnolence & $6(8.0)$ & $17(23.0)$ & $18(24.3)$ & $11(16.4)$ & $11(17.7)$ & $8(15.7)$ & \\
\hline Sedation & $5(6.7)$ & $7(9.5)$ & $11(14.9)$ & $9(13.4)$ & $11(17.7)$ & $4(7.8)$ & \\
\hline Dizziness & $8(10.7)$ & $11(14.9)$ & $4(5.4)$ & $4(6.0)$ & $4(6.5)$ & $2(3.9)$ & \\
\hline Anxiety & $23(30.7)$ & $18(24.3)$ & $18(24.3)$ & $12(17.9)$ & $9(14.5)$ & $6(11.8)$ & \\
\hline Agitation & $12(16.0)$ & $11(14.9)$ & $10(13.5)$ & $8(11.9)$ & $6(9.7)$ & $4(7.8)$ & \\
\hline Nausea & $2(2.7)$ & $2(2.7)$ & $1(1.4)$ & $2(3.0)$ & $1(1.6)$ & $1(2.0)$ & \\
\hline Vomiting & $1(1.3)$ & $1(1.4)$ & NA & NA & $1(1.6)$ & $1(2.0)$ & \\
\hline Worsening of psychosis & $3(4.0)$ & $3(4.1)$ & $2(2.7)$ & $1(1.5)$ & $3(4.8)$ & NA & \\
\hline \multicolumn{8}{|l|}{ Self report } \\
\hline Constipation & NA & $3(4.1)$ & $2(2.7)$ & $4(6.0)$ & $3(4.8)$ & NA & \\
\hline EPS & NA & $3(4.1)$ & $8(10.8)$ & $13(19.4)$ & $10(16.1)$ & $13(25.5)$ & \\
\hline \multicolumn{8}{|l|}{ ASEX } \\
\hline Total $(n=46)$ & $19.28 \pm 4.51$ & NA & NA & NA & $20.15 \pm 4.50$ & $20.35 \pm 3.97$ & 0.096 \\
\hline Male $(n=23)$ & $17.61 \pm 3.99$ & NA & NA & NA & $18.61 \pm 4.16$ & $19.00 \pm 3.57$ & 0.194 \\
\hline Female $(n=23)$ & $20.96 \pm 4.46$ & NA & NA & NA & $21.70 \pm 4.37$ & $21.70 \pm 3.96$ & 0.475 \\
\hline
\end{tabular}

Values are presented as number (\%) or mean \pm standard deviation.

$p$, one-way repeated measures ANOVA

EPS, Extrapyramidal Symptoms; ASEX, Arizona Sexual Experiences Scale; NA, not available.

Table 4. Changes from baseline in metabolism-related measures and prolactin level

\begin{tabular}{|c|c|c|c|c|c|c|}
\hline \multicolumn{2}{|c|}{ Variable } & \multirow{2}{*}{$\frac{\text { Baseline }}{59(93.7) / 4(6.3)}$} & \multirow{2}{*}{$\frac{\text { 8-week }}{34(87.2) / 5(12.8)}$} & \multirow{2}{*}{$\frac{t}{-2.600}$} & \multirow{2}{*}{$\frac{p^{1}}{0.014}$} & \multirow[t]{2}{*}{$p^{2}$} \\
\hline Fasting TG $(\sim 200)$ & Normal/abnormal & & & & & \\
\hline & Total/paired & $95.46 \pm 46.27 / 96.89 \pm 43.78 \quad(n=35)$ & $137.27 \pm 85.92 / 133.06 \pm 80.88$ & & & $<0.001$ \\
\hline \multirow[t]{2}{*}{ Fasting TC $(\geq 200)$} & Normal/abnormal & $60(90.9) / 6(9.1)$ & $30(73.2) / 11(26.8)$ & -2.996 & 0.005 & \\
\hline & Total/paired & $158.26 \pm 43.22 / 163.89 \pm 40.64 \quad(n=37)$ & $180.18 \pm 47.33 / 180.45 \pm 48.09$ & & & $<0.001$ \\
\hline \multirow[t]{2}{*}{ Fasting HDL (40-59) } & Normal/abnormal & $32(50.8) / 31(49.2)$ & $21(52.5) / 19(47.5)$ & -0.944 & 0.352 & \\
\hline & Total/paired & $48.12 \pm 11.70 / 49.29 \pm 10.79 \quad(n=35)$ & $56.06 \pm 49.13 / 57.46 \pm 52.35$ & & & 0.212 \\
\hline \multirow[t]{2}{*}{ Fasting LDL (70-159) } & Normal/abnormal & $46(78.0) / 13(22.0)$ & $31(88.6) / 4(11.4)$ & -2.791 & 0.009 & \\
\hline & Total/paired & $92.90 \pm 27.73 / 94.82 \pm 29.97 \quad(n=33)$ & $110.17 \pm 29.77 / 107.94 \pm 27.84$ & & & 0.010 \\
\hline \multirow[t]{2}{*}{ Fasting glucose $(\geq 100)$} & Normal/abnormal & $51(77.3) / 15(22.7)$ & $30(76.9) / 9(23.1)$ & -1.790 & 0.082 & \\
\hline & Total/paired & $91.34 \pm 17.27 / 93.53 \pm 19.87 \quad(n=36)$ & $94.89 \pm 9.02 / 94.36 \pm 9.31$ & & & 0.081 \\
\hline \multicolumn{7}{|l|}{$\mathrm{BMl}\left(\mathrm{kg} / \mathrm{m}^{2}\right)$} \\
\hline Total $(n=74 / 51)$ & Total/paired & $22.05 \pm 3.22 / 22.39 \pm 3.47$ & $23.63 \pm 3.31$ & -7.647 & $<0.001$ & \\
\hline Male $(n=41 / 26)$ & Total/paired & $21.90 \pm 3.25 / 22.19 \pm 3.51$ & $23.50 \pm 3.41$ & -5.130 & $<0.001$ & \\
\hline Female $(n=34 / 25)$ & Total/paired & $22.25 \pm 3.23 / 22.59 \pm 3.49$ & $23.77 \pm 3.27$ & -5.774 & $<0.001$ & \\
\hline \multicolumn{7}{|l|}{ Prolactin (ng/ml) } \\
\hline \multirow[t]{2}{*}{ Total } & Normal/abnormal & $34(54.8) / 28(45.2)$ & $2(4.8) / 40(95.2)$ & -4.885 & $<0.001$ & \\
\hline & Total/paired & $23.58 \pm 22.66 / 22.63 \pm 21.39(n=38)$ & $84.93 \pm 75.81 / 81.74 \pm 77.75$ & & & $<0.001$ \\
\hline \multirow[t]{2}{*}{ Male (2.5-17) } & Normal/abnormal & $21(55.3) / 17(44.7)$ & $1(4.3) / 22(95.7)$ & -5.231 & $<0.001$ & \\
\hline & Total/paired & $19.37 \pm 17.36 / 19.75 \pm 18.23 \quad(n=22)$ & $49.32 \pm 27.60 / 48.85 \pm 28.16$ & & & $<0.001$ \\
\hline \multirow[t]{2}{*}{ Female (1.9-25) } & Normal/abnormal & $13(54.2) / 11(45.8)$ & $1(5.3) / 18(94.7)$ & -4.082 & 0.001 & \\
\hline & Total/paired & $30.26 \pm 28.30 / 27.07 \pm 25.10 \quad(n=16)$ & $128.03 \pm 92.63 / 126.95 \pm 100.17$ & & & 0.006 \\
\hline
\end{tabular}

Values are presented as number (\%) or mean \pm standard deviation.

$p^{1}$, paired $t$-test between baseline and 8-week; $p^{2}$, McNemar test between baseline and 8-week.

TG, triglyceride; TC, total cholesterol; HDL, high-density lipoprotein; LDL, low-density lipoprotein; BMI, body mass index. 
as follows: akathisia (4.1\%), somnolence (2.7\%), EPS (2.7\%), and sedation (1.4\%; data not shown). Only one participant discontinued the medication due to severe akathisia. Assessment of movement disorders using the AIMS, BAS, and SAS revealed no significant changes between baseline and the last observation (data not shown). The ASEX scores did not change significantly over time (Table 3). However, assessed by the UKU at 8 weeks, several sexual side effects were reported: in males, reduced sexual desire $(2 / 34,5.9 \%)$ and erectile dysfunction $(2 / 34$, $5.9 \%)$ were reported; in females, amenorrhea $(5 / 32$, $15.6 \%)$ and galactorrhea $(1 / 32,3.1 \%)$ were reported. The fasting TG, total cholesterol, and LDL levels as well as the proportion of abnormal subjects at each level were both increased significantly during the 8-week treatment, but the fasting HDL and glucose levels did not significantly differ between baseline and endpoint (Table 4). The BMI increased significantly over time in both males and females. The mean change in weight between baseline and endpoint was $3.52 \pm 3.32 \mathrm{~kg}$ and the incidence of a clinically important increase in body weight $(\geq 7 \%$ weight gain) was $37.3 \%(19 / 51)$. The prolactin levels and proportion of abnormal subjects increased significantly over time. In particular, prolactin levels increased more in females than in males.

\section{DISCUSSION}

This study evaluated the efficacy and safety of paliperidone ER in patients with first-episode psychosis using a single-arm, open-label multicenter trial design. Our results showed that paliperidone ER is effective in improving psychopathology, cognitive impairment, and overall functioning scores and is well tolerated.

The dropout rate in our study was $32.0 \%$, which is slightly higher than the $25.14 \%$ observed in a 6 -week study of first-episode psychotic patients ${ }^{30)}$ but much lower compared with the $46.37 \%$ and $48.71 \%$ observed in 8 -week studies of first-episode schizophrenia patients. ${ }^{31,32)}$ The possible reasons that the nine patients $(12.0 \%)$ who could not be followed up after discharge from this study may include treatment refusal or visiting other hospitals. This result highlights the difficulty of maintaining continuous treatment after discharge in first-episode psychosis. The $6.7 \%$ discontinuation rate due to lack of efficacy in this study is similar to the rates reported for risperidone $\left(4.89 \%{ }^{32)}\right.$ and $\left.9 \%{ }^{33)}\right)$, olanzapine $\left(6.1 \%{ }^{34)}\right)$, and haloperidol $\left(8.9 \%{ }^{32)}\right.$ and $\left.12.1 \%^{34)}\right)$ in 8 -12-week trials with patients with first-episode psychosis. However, the rates were much lower than those reported for quetiapine (34.62\%), ziprasidone (20.73\%), and haloperidol (33.01\%) in the European First Episode Schizophrenia Trial. ${ }^{6}$ These findings suggest that the efficacy of paliperidone ER in first-episode psychosis is comparable or superior to that of other antipsychotics. However, the issue of the relative efficacy of atypical antipsychotics in first-episode schizophrenia patients should be investigated in future studies using well-designed methodologies and large sample sizes.

A significant improvement in psychopathology (lower PANSS and SANS scores) was observed over time and appeared as early as 1 week after administration of paliperidone ER. The result of this rapid effect is consistent with the previous paliperdione ER studies in which a significant improvement in the mean PANSS total score was evident from day $4 .{ }^{35,36)}$ This rapid action may result from initiating paliperidone ER at an effective dose due to OROS technology. However, the meta-analysis of 42 double-blind controlled studies showed the mean weekly PANSS or BPRS scores for various antipsychotics differed significantly from that at placebo at the very first week. ${ }^{37)}$ Furthermore, in previous studies ${ }^{32,38-42)}$ on the efficacy of risperidone in first-episode psychosis patients, the rapid action of risperidone (as early as 1 week) was never investigated. To clarify whether the rapid action of paliperidone ER is due to the advantage of OROS technology, a comparative study of paliperidone ER and risperidone should be conducted. Interestingly, significant improvement in cognitive functioning was also observed. However, this finding should be interpreted cautiously because it may reflect an indirect effect secondary to the improvement in positive symptoms or general psychopathology. Taken together the results show significant improvements in the positive and negative symptoms and cognitive functioning of patients with first-episode psychosis receiving a mean paliperidone ER dose of $8.74 \pm 2.78$ $\mathrm{mg}$ /day at the endpoint. Mean dosage of paliperidone ER for patients with first-episode of psychosis in this study was almost similar with that in other studies for patients with multiple-episode of psychosis. ${ }^{43-45)}$

The most frequently observed adverse events were akathisia, somnolence, and sedation. In particular, akathisia was observed most frequently at 3 weeks. The incidence of treatment-emergent akathisia over 8 weeks was $41.3 \%$ which is in contrast with that of previous studies $(17.4 \%$ and $9.8 \%$ with paliperidone ER at 6 and $9 \mathrm{mg}$ /day respectively), which were conducted mostly with multiple-episode patients. ${ }^{35,46)}$ In previous studies with paliper- 
idone ER in Korean patients with schizophrenia, whose mean duration of illness were about 10 years, incidence of akathisia were reported within $10 \%{ }^{47,48)}$ This discrepancy of akathisia rates among studies suggests that individuals with first-episode psychosis may be more likely to experience akathisia than those with multiple-episode psychosis when administered paliperidone ER. However, given that moderate akathisia persisted in only $4.1 \%$ of patients over two consecutive time points suggests that akathisia is usually mild and transient and can be successfully managed by prescribing concomitant medications. Some of the lipid profiles and BMIs increased significantly over time. These results may be due to the low levels of physical activities during admission or the direct effect of paliperidone ER. Regardless of the cause, proper attention should be paid to the occurrence of metabolic syndrome during the initial phase of treatment with paliperidone ER in first-episode psychosis. The incidence of hyperprolactinemia at the endpoint was $95.2 \%$ higher than the $74 \%$ reported in first-episode psychosis patients treated with risperidone. ${ }^{33)}$ The endpoint prolactin levels in males $(49.32 \pm 27.60 \mathrm{ng} / \mathrm{mL})$ and females $(128.03 \pm 92.63 \mathrm{ng} / \mathrm{mL})$ in the present study were similar to the levels observed in males $(45.3 \pm 25.4 \mathrm{ng} / \mathrm{mL})$ and females $(125.0 \pm 65.8 \mathrm{ng} / \mathrm{mL})$ in previous paliperidone ER studies. ${ }^{17)}$ The incidence of amenorrhea $(15.6 \%)$ was higher compared to those in risperidone $\left(12.03 \%{ }^{3)}\right.$ and $9.09 \%{ }^{42)}$ ) and other 6-week studies with paliperidone ER. ${ }^{17)}$ These findings suggest that, contrary to our hypothesis, the effects of paliperidone ER on prolactin levels and related sexual adverse events are greater than those of risperidone. These effects may be related to lower lipophilia and longer half-life of paliperidone and its reduced ability to cross the blood brain barrier because these factors increase the ability of paliperidone to affect the anterior pituitary gland, which is located outside the blood brain barrier. ${ }^{49,50)}$

The present study had several limitations. First, this study was open-label in design, which might have biased the findings. However, designing a randomized controlled trial in patients with first-episode psychosis may appear unethical and is very difficult to conduct. The duration of the study was also too short to evaluate the sexual and metabolic side effects of the drug. In conclusion, the present study demonstrated that paliperidone ER is effective in improving the positive and negative symptoms and cognitive functioning of patients with first-episode psychosis. Significant improvement was evident as early as the first week. The most frequent adverse events were akathisia, somnolence, anxiety, and sedation. However, because the adverse events were mild and transient in nature, they were well tolerated. Modest increases in weight and lipid profiles were noted. Although prolactin levels were substantially increased at the endpoint, related sexual side effects were limited.

\section{Acknowledgments}

This study was funded by the Janssen Pharmaceutical Company, Korea. The author would like to thank all the participants in the study and heavenly father who guides along the right pathway.

\section{REFERENCES}

1. Lieberman J, Jody D, Geisler S, Alvir J, Loebel A, Szymanski S, et al. Time course and biologic correlates of treatment response in first-episode schizophrenia. Arch Gen Psychiatry 1993;50:369-376.

2. Robinson DG, Woerner MG, Alvir JM, Geisler S, Koreen A, Sheitman B, et al. Predictors of treatment response from a first episode of schizophrenia or schizoaffective disorder. Am J Psychiatry 1999; 156:544-549.

3. McEvoy JP, Lieberman JA, Perkins DO, Hamer RM, Gu H, Lazarus A, et al. Efficacy and tolerability of olanzapine, quetiapine, and risperidone in the treatment of early psychosis: a randomized, double-blind 52-week comparison. Am J Psychiatry 2007; 164:1050-1060.

4. Walter G, Wiltshire C, Anderson J, Storm V. The pharmacologic treatment of the early phase of first-episode psychosis in youths. Can J Psychiatry 2001;46:803-809.

5. Opjordsmoen S, Melle I, Friis S, Haahr U, Johannessen JO, Larsen TK, et al. Stability of medication in early psychosis: a comparison between second-generation and low-dose first-generation antipsychotics. Early Interv Psychiatry 2009:3:58-65.

6. Kahn RS, Fleischhacker WW, Boter H, Davidson M, Vergouwe Y, Keet IP, et al; EUFEST study group. Effectiveness of antipsychotic drugs in first-episode schizophrenia and schizophreniform disorder: an open randomised clinical trial. Lancet 2008;371:1085-1097.

7. Chatterjee A, Chakos M, Koreen A, Geisler S, Sheitman B, Woerner $\mathrm{M}$, et al. Prevalence and clinical correlates of extrapyramidal signs and spontaneous dyskinesia in nevermedicated schizophrenic patients. Am J Psychiatry 1995; 152:1724-1729.

8. Curtis J, Watkins A, Rosenbaum S, Teasdale S, Kalucy M, Samaras K, et al. Evaluating an individualized lifestyle and life skills intervention to prevent antipsychotic-induced weight gain in first-episode psychosis. Early Interv Psychiatry 2015. doi: 10.1111/eip.12230. [Epub ahead of print]

9. Verma S, Liew A, Subramaniam M, Poon LY. Effect of treatment on weight gain and metabolic abnormalities in patients with first-episode psychosis. Aust $N Z$ J Psychiatry 2009;43:812-817.

10. Kampman O, Laippala P, Väänänen J, Koivisto E, Kiviniemi $\mathrm{P}, \mathrm{Kilkku} \mathrm{N}$, et al. Indicators of medication compliance in first-episode psychosis. Psychiatry Res 2002;110:39-48.

11. Robinson DG, Woerner MG, Alvir JM, Bilder RM, Hinrichsen GA, Lieberman JA. Predictors of medication discontinuation by patients with first-episode schizophrenia and schizoaffective disorder. Schizophr Res 2002;57:209219. 
12. Lautenschlager M, Heinz A. Paliperidone-ER: first atypical antipsychotic with oral extended release formulation. Expert Rev Neurother 2008;8:193-200.

13. Conley R, Gupta SK, Sathyan G. Clinical spectrum of the osmotic-controlled release oral delivery system (OROS), an advanced oral delivery form. Curr Med Res Opin 2006;22: 1879-1892.

14. Sheehan JJ, Reilly KR, Fu DJ, Alphs L. Comparison of the peak-to-trough fluctuation in plasma concentration of long-acting injectable antipsychotics and their oral equivalents. Innov Clin Neurosci 2012;9:17-23.

15. Shah S, Joshi D. Tolerability and efficacy of paliperidone ER compared to olanzapine in the treatment of schizophrenia: A randomized, double-blind, multicentric trial. Ind Psychiatry J 2011;20:25-31.

16. Canuso CM, Schooler N, Carothers J, Turkoz I, KosikGonzalez C, Bossie CA, et al. Paliperidone extended-release in schizoaffective disorder: a randomized, controlled study comparing a flexible dose with placebo in patients treated with and without antidepressants and/or mood stabilizers. $J$ Clin Psychopharmacol 2010;30:487-495.

17. Meltzer HY, Bobo WV, Nuamah IF, Lane R, Hough D, Kramer $\mathrm{M}$, et al. Efficacy and tolerability of oral paliperidone extended-release tablets in the treatment of acute schizophrenia: pooled data from three 6-week, placebocontrolled studies. J Clin Psychiatry 2008;69:817-829.

18. Si T, Tan Q, Zhang K, Wang Y, Rui Q. An open-label, flexible-dose study of paliperidone extended-release in Chinese patients with first-onset psychosis. Neuropsychiatr Dis Treat 2015;11:87-95.

19. First MB, Spitzer RL, Gibbon M, Williams JBW. Structured clinical interview for DSM-IV Axis I Disorders SCID-I: clinician version, administration booklet. Washington, DC: American Psychiatric Press;1997.

20. Kay SR, Fiszbein A, Opler LA. The positive and negative syndrome scale (PANSS) for schizophrenia. Schizophr Bull 1987;13:261-276.

21. Sanger TM, Lieberman JA, Tohen M, Grundy S, Beasley C $\mathrm{Jr}$, Tollefson GD. Olanzapine versus haloperidol treatment in first-episode psychosis. Am J Psychiatry 1999;156:79-87.

22. Andreasen NC. The Scale for the Assessment of Negative Symptoms (SANS): conceptual and theoretical foundations. Br J Psychiatry Suppl 1989;(7):49-58.

23. Keefe RS, Poe M, Walker TM, Kang JW, Harvey PD. The Schizophrenia Cognition Rating Scale: an interview-based assessment and its relationship to cognition, real-world functioning, and functional capacity. Am J Psychiatry 2006:163:426-432.

24. American Psychiatric Association; APA Work Group to Revise DSM-III. Diagnostic and statistical manual of mental disorders: DSM-III-R. 3rd ed. Washington, DC: American Psychiatric Press; 1987.

25. Simpson GM, Angus JW. A rating scale for extrapyramidal side effects. Acta Psychiatr Scand Suppl 1970;212:11-19.

26. Barnes TR. A rating scale for drug-induced akathisia. Br J Psychiatry 1989;154:672-676.

27. Guy W, editor. ECDEU Assessment Manual for Psychopharmacology. Rockville, MD:US Department of Heath, Education, and Welfare Public Health Service Alcohol, Drug Abuse, and Mental Health Administration;1976.

28. McGahuey CA, Gelenberg AJ, Laukes CA, Moreno FA, Delgado PL, McKnight KM, et al. The Arizona Sexual Experience Scale (ASEX): reliability and validity. J Sex Marital Ther 2000;26:25-40.

29. Lingjaerde O, Ahlfors UG, Bech P, Dencker SJ, Elgen K.
The UKU side effect rating scale. A new comprehensive rating scale for psychotropic drugs and a cross-sectional study of side effects in neuroleptic-treated patients. Acta Psychiatr Scand Suppl 1987;334:1-100.

30. Emsley R, Berwaerts J, Eerdekens M, Kramer M, Lane R, Lim $\mathrm{P}$, et al. Efficacy and safety of oral paliperidone extended-release tablets in the treatment of acute schizophrenia: pooled data from three 52-week open-label studies. Int Clin Psychopharmacol 2008;23:343-356.

31. Gaebel W, Möller HJ, Buchkremer G, Ohmann C, Riesbeck $\mathrm{M}$, Wölwer W, et al. Pharmacological long-term treatment strategies in first episode schizophrenia--study design and preliminary results of an ongoing RCT within the German Research Network on Schizophrenia. Eur Arch Psychiatry Clin Neurosci 2004;254:129-140.

32. Möller HJ, Riedel M, Jäger M, Wickelmaier F, Maier W, Kühn KU, et al. Short-term treatment with risperidone or haloperidol in first-episode schizophrenia: 8-week results of a randomized controlled trial within the German Research Network on Schizophrenia. Int J Neuropsychopharmacol 2008; 11:985-997.

33. Schooler N, Rabinowitz J, Davidson M, Emsley R, Harvey PD, Kopala L, et al. Early Psychosis Global Working Group. Risperidone and haloperidol in first-episode psychosis: a long-term randomized trial. Am J Psychiatry 2005; 162:947-953.

34. Lieberman JA, Tollefson G, Tohen M, Green AI, Gur RE, Kahn R, et al; HGDH Study Group. Comparative efficacy and safety of atypical and conventional antipsychotic drugs in first-episode psychosis: a randomized, double-blind trial of olanzapine versus haloperidol. Am J Psychiatry 2003; 160:1396-1404.

35. Davidson M, Emsley R, Kramer M, Ford L, Pan G, Lim P, et al. Efficacy, safety and early response of paliperidone extended-release tablets (paliperidone ER): results of a 6-week, randomized, placebo-controlled study. Schizophr Res 2007;93:117-130.

36. Kane JM, Correll CU, Goff DC, Kirkpatrick B, Marder SR, Vester-Blokland E, et al. A multicenter, randomized, doubleblind, placebo-controlled, 16-week study of adjunctive aripiprazole for schizophrenia or schizoaffective disorder inadequately treated with quetiapine or risperidone monotherapy. $J$ Clin Psychiatry 2009;70:1348-1357.

37. Agid O, Kapur S, Arenovich T, Zipursky RB. Delayed-onset hypothesis of antipsychotic action: a hypothesis tested and rejected. Arch Gen Psychiatry 2003;60:1228-1235.

38. Emsley RA. Risperidone in the treatment of first-episode psychotic patients: a double-blind multicenter study. Risperidone Working Group. Schizophr Bull 1999;25:721-729.

39. Kopala LC, Fredrikson D, Good KP, Honer WG. Symptoms in neuroleptic-naive, first-episode schizophrenia: response to risperidone. Biol Psychiatry 1996;39:296-298.

40. Merlo MC, Hofer H, Gekle W, Berger G, Ventura J, Panhuber I, et al. Risperidone, $2 \mathrm{mg} /$ day vs. $4 \mathrm{mg} /$ day, in first-episode, acutely psychotic patients: treatment efficacy and effects on fine motor functioning. J Clin Psychiatry 2002;63:885-891.

41. Yap HL, Mahendran R, Lim D, Liow PH, Lee A, Phang S, et al. Risperidone in the treatment of first episode psychosis. Singapore Med J 2001;42:170-173.

42. Zalsman G, Carmon E, Martin A, Bensason D, Weizman A, Tyano S. Effectiveness, safety, and tolerability of risperidone in adolescents with schizophrenia: an open-label study. J Child Adolesc Psychopharmacol 2003;13:319-327.

43. Kramer M, Simpson G, Maciulis V, Kushner S, Vijapurkar 
$\mathrm{U}$, Lim P, et al. Paliperidone extended-release tablets for prevention of symptom recurrence in patients with schizophrenia: a randomized, double-blind, placebo-controlled study. J Clin Psychopharmacol 2007;27:6-14.

44. Peuskens J, Rubio G, Schreiner A. Dosing and switching of paliperidone ER in patients with schizophrenia: recommendations for clinical practice. Ann Gen Psychiatry 2014; 13:10.

45. Schmauss M, Jukić V, Siracusano A, Bidzan L, Badescu $\mathrm{GM}$, Maciulis $\mathrm{V}$, et al. Flexible dosing with paliperidone ER in the treatment of patients with acutely exacerbated schizophrenia: results from a single-arm, open-label study. Curr Med Res Opin 2012;28:1395-1404.

46. Marder SR, Kramer M, Ford L, Eerdekens E, Lim P, Eerdekens $\mathrm{M}$, et al. Efficacy and safety of paliperidone extended-release tablets: results of a 6-week, randomized, placebo-controlled study. Biol Psychiatry 2007;62:13631370 .
47. Kim SW, Chung YC, Lee YH, Lee JH, Kim SY, Bae KY, et al. Paliperidone ER versus risperidone for neurocognitive function in patients with schizophrenia: a randomized, openlabel, controlled trial. Int Clin Psychopharmacol 2012;27: 267-274.

48. Kim SW, Yoon JS, Kim YS, Ahn YM, Kim CE, Go HJ, et al. The effect of paliperidone extended release on subjective well-being and responses in patients with schizophrenia. Prog Neuropsychopharmacol Biol Psychiatry 2012; 38:228-235.

49. de Leon J, Wynn G, Sandson NB. The pharmacokinetics of paliperidone versus risperidone. Psychosomatics 2010;51: 80-88.

50. Gahr M, Kölle MA, Schönfeldt-Lecuona C, Lepping P, Freudenmann RW. Paliperidone extended-release: does it have a place in antipsychotic therapy? Drug Des Devel Ther 2011;5:125-146. 